\title{
Biosynthesis of Silver Chloride Nanoparticles Using Bacillus subtilis MTCC 3053 and Assessment of Its Antifungal Activity
}

\author{
Kanniah Paulkumar, Shanmugam Rajeshkumar, Gnanadhas Gnanajobitha, \\ Mahendran Vanaja, Chelladurai Malarkodi, and Gurusamy Annadurai
}

Environmental Nanotechnology Division, Sri Paramakalyani Centre for Environmental Sciences, Manonmaniam Sundaranar University, Alwarkurichi, Tamil Nadu 627412, India

Correspondence should be addressed to Gurusamy Annadurai; gannadurai@hotmail.com

Received 29 June 2013; Accepted 28 July 2013

Academic Editors: Z. Jiang, P. S. Khiew, and N. Revaprasadu

Copyright (C) 2013 Kanniah Paulkumar et al. This is an open access article distributed under the Creative Commons Attribution License, which permits unrestricted use, distribution, and reproduction in any medium, provided the original work is properly cited.

\begin{abstract}
The present investigation reported the synthesis of silver chloride nanoparticles using Bacillus subtilis. The adsorption of colloidal silver chloride nanoparticles showed an intense peak at the wavelength of $400 \mathrm{~nm}$ after $20 \mathrm{hrs}$ of biomass incubation. The size of the silver nanoparticles ranges from 20 to $60 \mathrm{~nm}$ which was obtained from transmission electron microscope (TEM). The X-ray diffraction (XRD) pattern confirmed the crystalline nature of the nanoparticles. The bright circular spots of selected diffraction area (SAED) pattern also confirmed the good crystalline nature of the silver chloride nanoparticles with high magnification of TEM images. The presence of nitrate reductase enzyme in the cellular membrane of $B$. subtilis was confirmed by sodium dodecyl (SDS) polyacrylamide gel electrophoresis and it was found that the molecular weight is $37 \mathrm{kDa}$. The possible functional groups of the reductase enzyme in B. subtilis were identified by Fourier transform infrared spectroscopy (FTIR). Finally, antifungal activity of silver chloride nanoparticle was examined against Candida albicans, Aspergillus niger, and Aspergillus flavus. We conclude that the synthesis of silver chloride nanoparticles using microorganisms is more economical and simple. The antifungal property of silver chloride nanoparticles will play a beneficial role in biomedical nanotechnology.
\end{abstract}

\section{Introduction}

After a glorious invention of microorganisms by "Louis Pasteur," it could spread all over the field of life sciences and delivered its beneficial applications to improve human health. From 19th century onwards, the microorganisms have been utilized for making dairy products, beverages (alcoholic), enzymes, proteins production, and so forth [1]. In modern microbiology, the interaction between metals and microbes brings a great attention to exclude the heavy metals from the environment $[1,2]$. The presence of active biomolecules like enzymes in the cell wall membrane of microorganisms plays an adverse effect in degradation of toxic metals by the way of bioremediation process $[1,3]$. Nowadays, the biosynthesis of nanomaterials like inorganic nanoparticles and semiconductor nanoparticles using microorganisms such as bacteria $[4$, $5]$ and fungi $[6,7]$ is a popularly known field and attracts more interest day-by-day due to its ecofriendly nature. Traditionally, nanoparticles have been synthesized through physical [8-10] and chemical methods [11-13]. However, these methods are not environmentally benign. Some of the chemicals such as thiophenol [14] and thiourea [15] have been used in the synthesis process to avoid the particle agglomeration. But these chemicals may cause adverse effects in the environment during large-scale production [16]. There are few reports available to demonstrate the possible mechanisms involved in the production of nanoparticles [4, 17-19]. Generally, researchers may suggest that the defensive mechanism of microorganisms as well as plants plays a key role in the nanoparticle synthesis process [20-22]. Recently, Gopinath et al. reported the synthesis of silver chloride nanoparticles using the leaf extract of Cissus quadrangularis Linn [23]. Mostly, silver chloride nanoparticles and silver chloridebased nanocomposites have been used for photocatalytic 
degradation studies $[24,25]$. In addition, they are also used as antibacterial agent and sensor in few reports [23, 26]. Generally, microemulsion, electrospinning, and ultrasound irradiation methods are used for the production of silver chloride nanoparticles [27-29]. Nowadays, there is an essential need to synthesize the nanoparticles without affecting the environment. Therefore, most biobased routes are preferred to synthesize the nanoparticles.

Bacillus sp. is a fine metal reducing bacteria used for the removal of toxic metals such as arsenic [30], zinc [31], cadmium [32], and lead [33]. Previously, Pugazhenthiran et al. used the Bacillus sp. for the synthesis of silver nanoparticles [34]. Thereby, based on the protective mechanism of bacteria [21,31], we have demonstrated the synthesis of silver chloride nanoparticles by using Bacillus subtilis MTCC 3053. Further, the synthesized silver chloride nanoparticles are characterized by XRD, SEM, TEM, EDAX, and FTIR analysis. The enzyme responsible for synthesis of silver chloride nanoparticles is identified by SDS gel electrophoresis. The antifungal activity of silver chloride nanoparticle is examined against Candida albicans, Aspergillus niger, and Aspergillus flavus (laboratory cultures).

\section{Materials and Methods}

2.1. Bacterial Strain and Its Growth Conditions. The test strain Bacillus subtilis MTCC 3053 was obtained from Microbial Type Culture Collection and Gene Bank, Chandigarh, India. All the chemicals, media, and analytical reagents used in this present work were purchased from Hi-Media Laboratories Pvt. Ltd. (Mumbai, India). In biosynthesis of nanoparticles, the bacterial culture was grown nutrient broth and the flasks were incubated on orbital shaker and agitated at $220 \mathrm{rpm}$ at room temperature. After $24 \mathrm{~h}$ incubation, the harvested biomass was transferred into sterilized flask for nanoparticle synthesis. The culture was maintained by subculturing every 2 weeks at room temperature in nutrient agar plates.

2.2. Microbe-Mediated Synthesis of Silver Chloride Nanoparticles. The bacterial culture was inoculated into $50 \mathrm{~mL}$ sterile nutrient broth and harvested at different points of time $(6,12$, 18 , and $24 \mathrm{hrs}$ ). About $1 \mathrm{mM}$ of silver nitrate was mixed with the obtained biomass after different time intervals. Then, the Erlenmeyer flasks were incubated at $37^{\circ} \mathrm{C}$ under agitation at $220 \mathrm{rpm}$ for $24 \mathrm{~h}$.

2.3. Characterization of Silver Nanoparticles. The silver chloride nanoparticles synthesized at different time intervals were evaluated by UV-vis spectroscopy. The biomass was treated with silver nitrate and then centrifuged at $10,000 \mathrm{rpm}$ for $10 \mathrm{~min}$. The centrifugation process was repeated for 4-5 times and finally the obtained pellet was washed with distilled water. The pellet was collected and dried in hot air oven. The powdered particles were scanned on a Philips scanning electron microscope (SEM) and the crystalline nature was identified by using XDL 3000 powder X-ray diffractometer. The size and morphology of the air-dried silver chloride nanoparticles were characterized by TEM analysis (Philips
CM200). The presence of elemental silver and chloride ions in the solution mixture was analysed by EDAX analysis and the FTIR spectra of metallic powdered silver chloride nanoparticle were measured in the range of $3500-500 \mathrm{~cm}^{-1}$ with resolution of $4 \mathrm{~cm}^{-1}$. The FTIR spectrum was performed to analyse the possible functional groups on the silver chloride nanoparticle involved in the interaction between the reducing agent like proteins and/or enzymes of microorganism and silver nitrate.

2.4. SDS Gel Electrophoresis. About $100 \mathrm{~mL}$ of biomass was transferred into a beaker and the beaker was kept chilled by placing it in an ice tray. The ammonium sulphate (75\% saturation) was added very slowly with continuous stirring (add a small amount at a time and then allow it to dissolve and add the remaining solution). The suspension was stirred for $1 \mathrm{hr}$ and kept overnight at $4^{\circ} \mathrm{C}$ and then centrifuged at 10,000 rpm for $15 \mathrm{~min}$ to obtain the precipitate. The supernatant was removed and the pellet containing the precipitated protein was dissolved in $1 \mathrm{M}$ phosphate buffer $(\mathrm{pH}$ 7.0) for dialysis. Dialysis membrane tubes were cut and washed inside and outside of the tube with distilled water using a squeeze bottle. The above step was repeated again and finally the dialysis tube was washed three times with distilled water. Water was removed from the tubes and the obtained ammonium sulfate precipitate (in solution) was introduced using a pipette. After dialysis, the obtained desalted protein was concentrated against crystals of sucrose and kept in the refrigerator at $4^{\circ} \mathrm{C}$ for further assay. The protein was investigated by running the samples in SDS-PAGE as per standard procedure. The sample was dissolved in sample buffer and heated the sample at $80^{\circ} \mathrm{C}$ for $10 \mathrm{~min}$. The sample was cooled and mixed with bromophenol blue and loaded in the gel. After running of protein sample in the gel, the gel was stained with Coomassie brilliant blue and observed under gel documentation system (Lark, USA).

2.5. Antifungal Activity of Silver Chloride Nanoparticles. Agar disc diffusion method was used to assay the fungicidal effect of synthesized silver chloride nanoparticles on Rose Bengal agar plates against the strains of Candida albicans, Aspergillus flavus, and Aspergillus niger. A single loop full of test strain was grown in Rose Bengal agar and incubated at dark condition. After $48 \mathrm{~h}$ incubation, a loop full spore were mixed into the $10 \mathrm{~mL}$ of sterile distilled water and swapped on the Rose Bengal agar medium. The silver chloride nanoparticles were taken at different concentrations $(50 \mu \mathrm{L}, 100 \mu \mathrm{L}$, and $150 \mu \mathrm{L})$ and impregnated with sterile disc and placed over the surface of the medium to assess the antifungal effect of the silver chloride nanoparticles. After incubation at $37^{\circ} \mathrm{C}$ for $24-$ 48 hours, the zone of inhibition was measured.

\section{Results and Discussion}

3.1. Visual Identification. The present investigation deals with the synthesis of silver chloride nanoparticles by using ecofriendly based microbe-mediated process. Initially, the formation of silver nanoparticles is visually identified by 


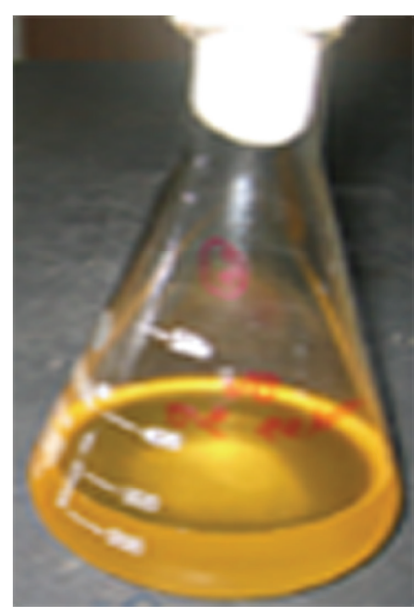

(a)

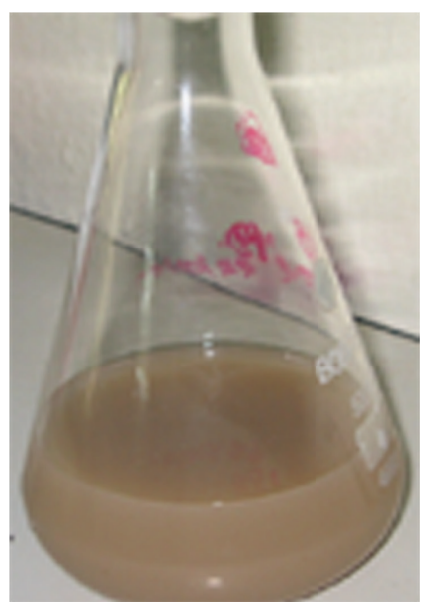

(b)

Figure 1: Visual identification of synthesis of silver chloride nanoparticles using B. subtilis.

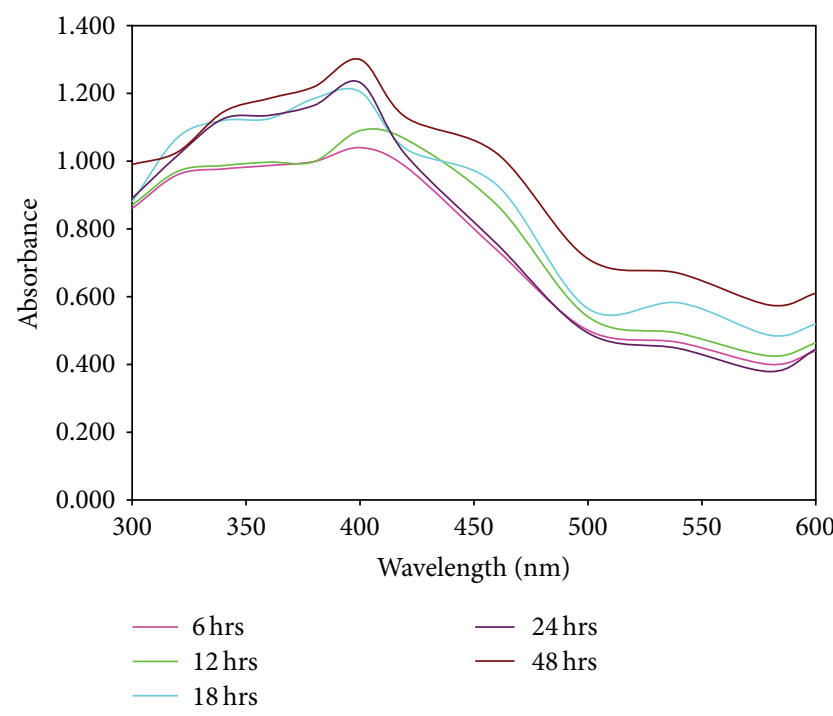

FIGURE 2: UV-vis spectra recorded the formation of silver chloride nanoparticle. The silver nitrate $1 \mathrm{mM}$ was added to Bacillus subtilis and incubated at different growth periods like $6,12,18,24$, and $48 \mathrm{~h}$.

the appearance of brown colour in the reaction mixture (B. subtilis with silver nitrate). The color is changed from pale yellow to brownish color (Figures 1(a) and 1(b)) clearly indicating the formation of silver chloride nanoparticles [23]. The color changes are compared with the control (without addition of silver nitrate and showed no color changes) (Figure 1(a)). Further, the silver chloride nanoparticles are purified by repeated centrifugation process for 3 to 4 times at $10,000 \mathrm{rpm}$ and the pellet is dried in hot air oven. The dried silver chloride nanoparticles are characterized by SEM, EDAX, XRD, TEM, and FTIR.
3.2. UV-Vis Spectroscopy Analysis. The biomediated synthesis of silver chloride nanoparticles is primarily characterized by UV-vis spectroscopy, which is a favorable technique to analyse the formation of nanoparticles [5]. Figure 2 shows a strong and broad peak observed at $400 \mathrm{~nm}$ proved that the synthesis of silver chloride nanoparticles due to the impact of $B$. subtilis biomass. The observed peak is assigned to the surface plasmon that was well documented for various metal nanoparticles with sizes ranging from 2 to $100 \mathrm{~nm}$ [35-37]. The dark brown color is observed more at the stationary phase, that is, at $24-48 \mathrm{hrs}$ incubation. The color formation occurred due to the presence of enormous energetic microbial cells which enhances the silver chloride nanoparticle production (Figure 1(b)). Initially, at 6 and $12 \mathrm{hrs}$ incubation, the synthesized silver chloride nanoparticles were absorbed at $420 \mathrm{~nm}$. After that, the particles were absorbed at $400 \mathrm{~nm}$ due to the contamination of chloride ions from sodium chloride (nutrient broth) and resulted in the formation of silver chloride nanoparticles. Recently, Gopinath et al. have reported the synthesis of silver chloride by using the leaf extracts of Cissus quadrangularis Linn [23]. They have illustrated that the presence of chloride ions in the leaf extract might be a responsible source for the formation of silver chloride nanoparticles. Generally, the silver nitrate is used as a precursor for the synthesis of silver nanoparticles, whereas, herein, the chloride ions from sodium chloride in the culture medium bound to the silver metal ions and form silver chloride nanoparticles. At 6 and $12 \mathrm{hrs}$ incubation, the formation of large-sized silver chloride nanoparticles shows wide surface plasmon resonance (SPR) band at longer wavelength. After $12 \mathrm{hrs}$, slight narrow SPR peak is raised at $400 \mathrm{~nm}$ revealing the formation of small-sized silver chloride nanoparticles. The observation of SPR peaks at 400, 460, and $540 \mathrm{~nm}$ at $48 \mathrm{hrs}$ incubation indicates the synthesis of uneven shaped polydispersed silver chloride nanoparticles. Moreover, the formation of SPR peak at 500-580 nm at 


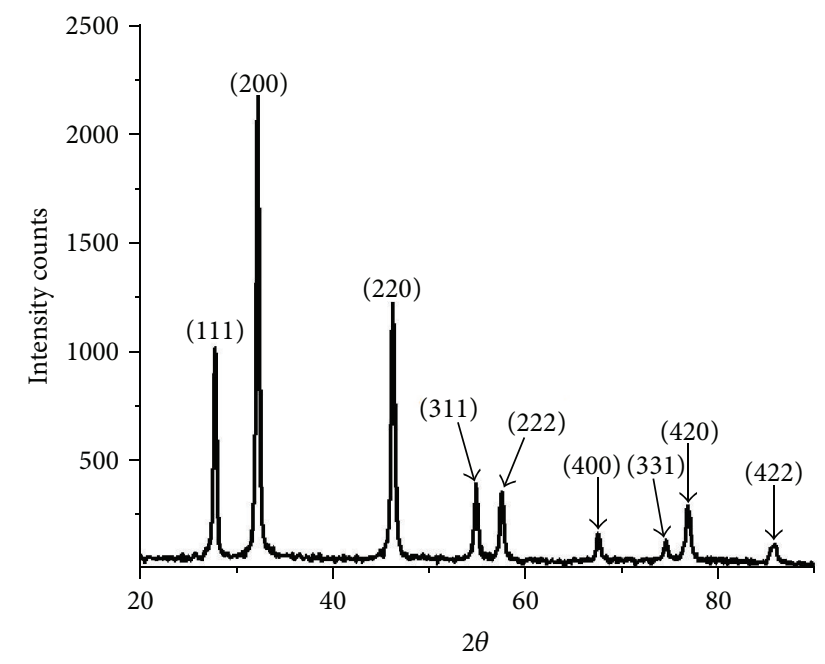

FIGURE 3: XRD of the air-dried silver chloride nanoparticles synthesized by B. subtilis.

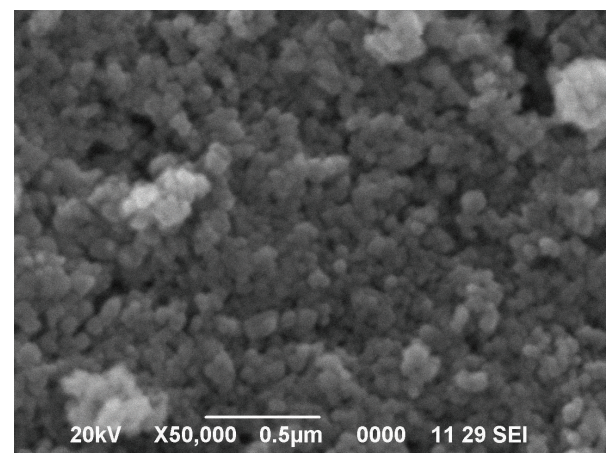

FIGURE 4: SEM analysis of silver chloride nanoparticles. SEM image shows spherical-shaped silver chloride nanoparticles synthesized by $B$. subtilis. The particle size was characterized in the range of 20$60 \mathrm{~nm}$ for B. subtilis (scale bar-500 $\mathrm{nm}$ ).

$48 \mathrm{hrs}$ incubation indicates the aggregation of silver chloride nanoparticles. The SEM image also confirmed the aggregation of silver chloride nanoparticles (Figure 4).

3.3. XRD. The XRD spectra were used to confirm the crystalline nature of the silver chloride nanoparticles synthesized by $B$. subtilis and the pattern is exhibited in Figure 3. The XRD spectrum of silver chloride nanoparticles synthesized by $B$. subtilis exhibits strong peaks at $2 \theta$ values of $27.9^{\circ}, 32.3^{\circ}, 46.3^{\circ}$, $55.0^{\circ}, 57.6^{\circ}, 67.6^{\circ}, 74.6^{\circ}, 76.9^{\circ}$, and $85.7^{\circ}$ corresponding to (11 1), (2 00 ), (2 20$)$, (311), (2 2 2), (4 00$),(331),(420)$, and (4 2 2) planes, respectively. The XRD spectrum is compared with the exited spectrums of standard silver chloride that have been published by Joint Committee on Powder Diffraction Standards (JCPDS file no. 85-1355). The average size of the synthesized silver chloride nanoparticle is estimated from

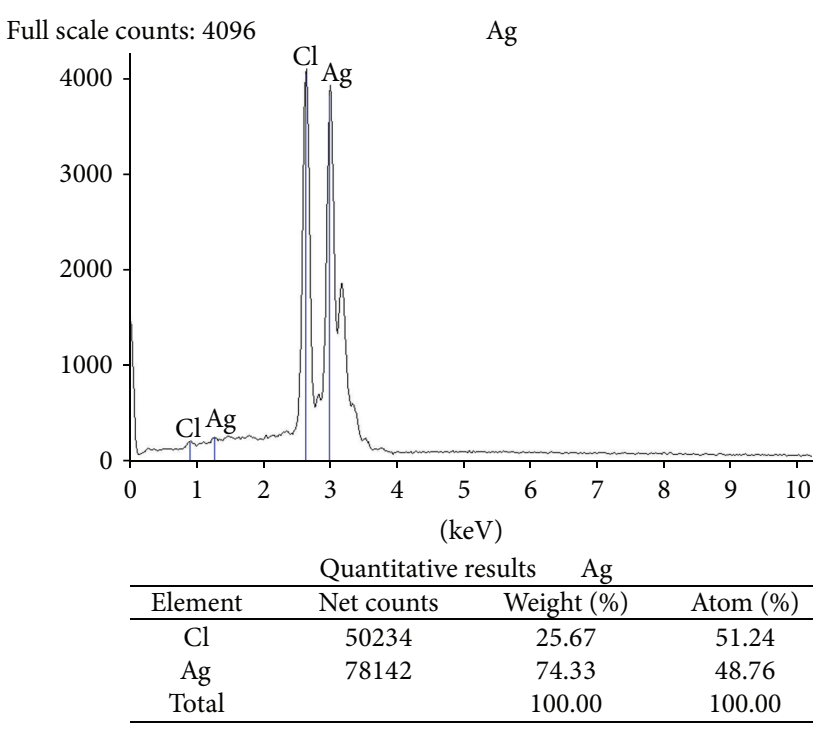

FIGURE 5: EDAX analysis of silver chloride nanoparticle synthesized by B. subtilis.

the broadening plane $\left(\begin{array}{lll}2 & 0 & 0\end{array}\right)$ by using the Debye-Scherrer equation (1):

$$
D=\frac{K \lambda}{\beta \cos \theta},
$$

where $D$ is the average particle size, $k$ is the shape factor (constant 0.9 ), $\lambda$ is the $\mathrm{X}$-ray wavelength (1.5406 $\AA$ ), $\beta$ is the full width at half maximum of the peak (FWHM), and $\theta$ is the diffraction angle. The average size of the particle was around $47 \mathrm{~nm}$, which is well matched with the result of TEM analysis of silver chloride nanoparticles.

3.4. SEM and EDAX Analysis. The SEM image confirmed that the synthesized silver chloride nanoparticles are polydispersed and the size ranges from 20 to $60 \mathrm{~nm}$ (scale bar $500 \mathrm{~nm}$ ) (Figure 4). The synthesized nanoparticles are aggregated with each other due to the adequate amount of stabilizing agent. The EDAX analysis of silver chloride nanoparticles synthesized using B. subtilis (Figure 5) exhibited that the silver and chloride are the parts of elemental composition and the strong absorption peak that is observed at $3 \mathrm{keV}$ also denotes the presence of silver nanoparticles.

3.5. TEM and SAED. TEM analysis is performed to identify the shape of the nanoparticles. The purified silver chloride nanoparticles are characterized by TEM that is shown in Figure 6(a), which exhibits the polydispersed silver chloride nanoparticles with an average particle size of $47 \mathrm{~nm}$ (scale bar $100 \mathrm{~nm}$ ), obtained using B. subtilis, though the synthesized silver chloride nanoparticles are predominantly spherical in shape (Figure 6(a)). The SAED pattern shows that the pointed spots indicate the face centered cubic crystalline nature of metallic silver chloride nanoparticles (Figure 6(b)). 


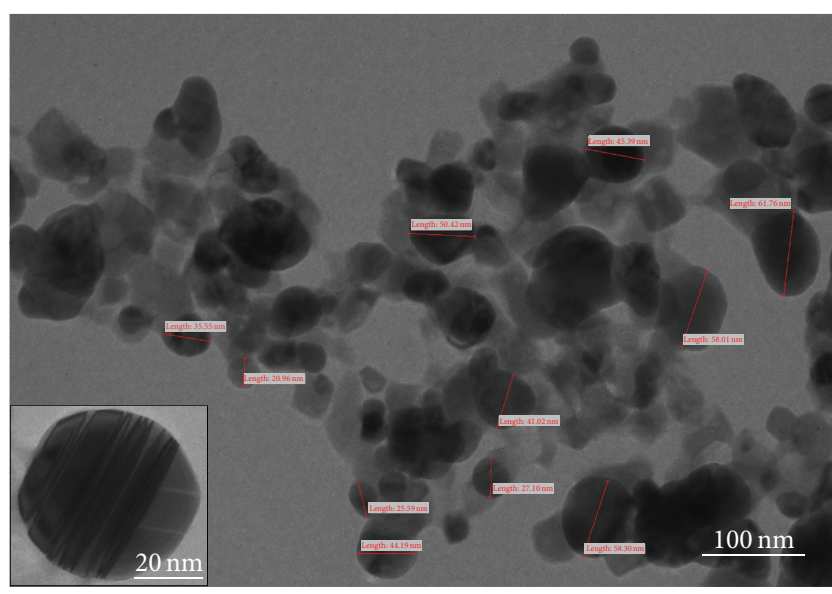

(a)

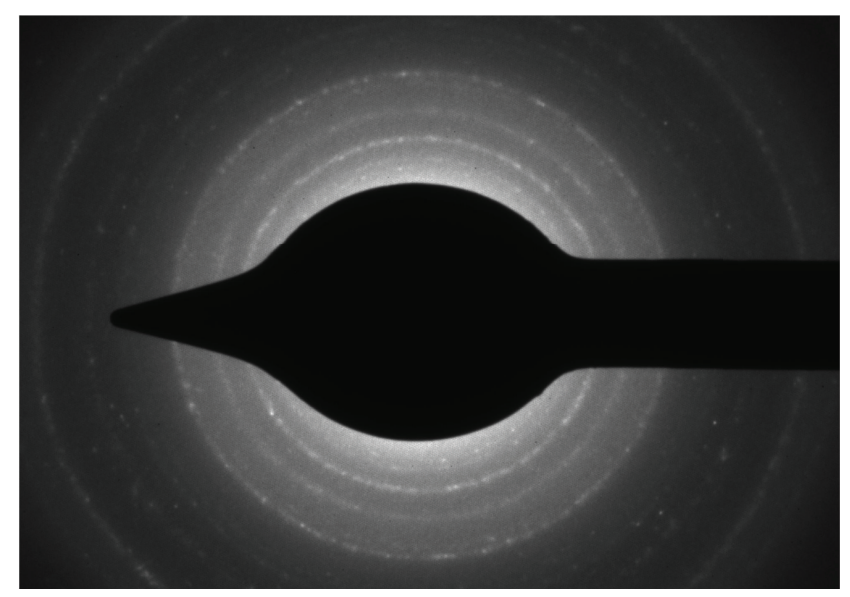

(b)

FIGURE 6: (a) TEM analysis of silver chloride nanoparticles (scale bar-100 nm). Inset (a) shows single spherical-shaped silver nanoparticles (scale bar $20 \mathrm{~nm}$ ). The average size of silver chloride nanoparticles synthesized by B. subtilis was around $43 \mathrm{~nm}$. (b) SAED pattern of silver chloride nanoparticles synthesized by B. subtilis.

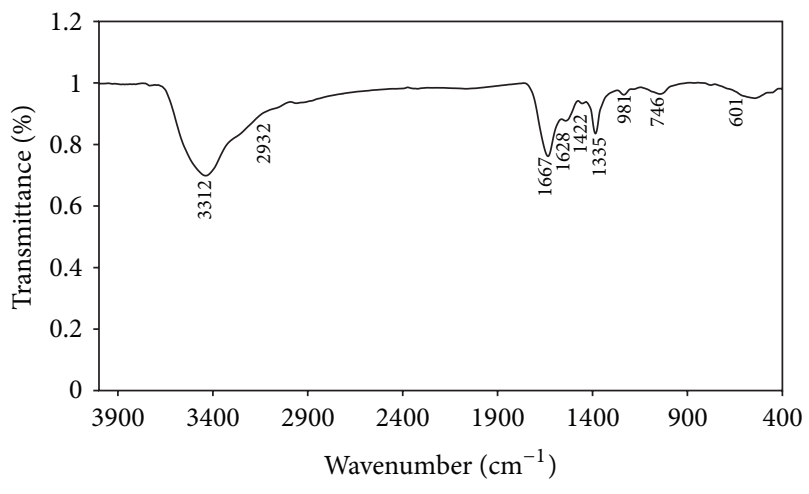

FIGURE 7: FTIR spectrum of silver chloride nanoparticles.

3.6. FTIR Analysis. FTIR analysis is performed to identify the presence of possible functional groups in the biomass of B. subtilis. These functional groups are responsible for the reduction and stabilization of biomanufactured silver nanoparticle. Figure 7 exhibits the FTIR measurement of silver nanoparticle and the bands are observed at $3437 \mathrm{~cm}^{-1}$ and $2322 \mathrm{~cm}^{-1}$ corresponding to $\mathrm{NH}$ stretching vibration of primary and secondary amines in the protein molecule $[35,36]$. The bands observed at $1634 \mathrm{~cm}^{-1}$ and $1541 \mathrm{~cm}^{-1}$ are attributed to $\mathrm{C}=\mathrm{C}$ (Alkenes) and another band that is observed at $1384 \mathrm{~cm}^{-1}$ is assigned to $\mathrm{C}-\mathrm{H}$ bending vibrations of methyl $\left(\mathrm{CH}_{3}\right)$ group which is present in protein $[7,38]$. The absorption peaks are observed at $1235 \mathrm{~cm}^{-1}$ and $1045 \mathrm{~cm}^{-1}$ are assigned $-\mathrm{C}-\mathrm{O}$ and $-\mathrm{C}=\mathrm{O}$ of aromatic acid and esters, respectively [38]. These functional groups might be present in the nitrate reductase which is located in the cell surface of $B$. subtilis. Nitrate reductase activity is mainly dependent on the growth phase of biomass and the silver chloride nanoparticle is synthesized vigorously at the stationary phase by the active response of nitrate reductase with silver nitrate.

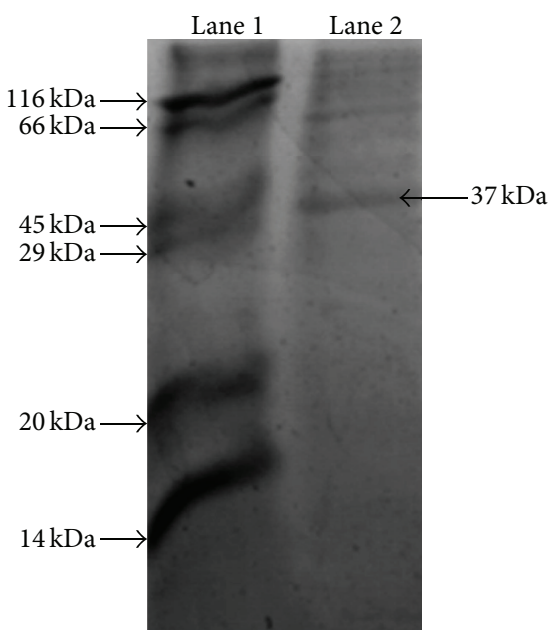

FIGURE 8: SDS gel electrophoresis of extracellular protein. Lane 1 contains marker protein with molecular weight galactosidase$116 \mathrm{kDa}$, bovine serum albumin $-66 \mathrm{kDa}$, ovalbumin $-45 \mathrm{kDa}$, carbonic anhydrase-29 kDa, soybean trypsin inhibitor-20.1 kDa, and lysozyme $-14.4 \mathrm{kDa}$. Lane 2 contains extracellular protein of $B$. subtilis and the arrow indicates the presence of a protein with molecular weight of $37 \mathrm{kDa}$.

3.7. SDS Gel Electrophoresis. The occurrence of cellular proteins in B. subtilis was extracted by ammonium precipitation method and the molecular weight of the protein is identified by SDS-PAGE (Figure 8). In that, lane 1 contains the marker protein and lane 2 loaded with extracellular protein exhibits an intense band with the molecular weight of $37 \mathrm{kDa}$ that might be the nitrate reductase enzyme which is responsible for synthesis of silver chloride nanoparticles. Similarly, Jain et al. have achieved that the presence of $32 \mathrm{kDa}$ reductase enzyme in Aspergillus flavus NJP08 acts as a reducing agent for the production of silver chloride nanoparticles from silver ions [20]. The nitrate reductase is one of the enzymes present 


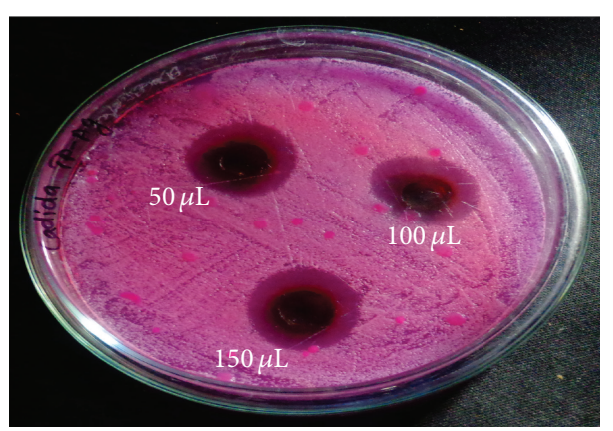

(a)

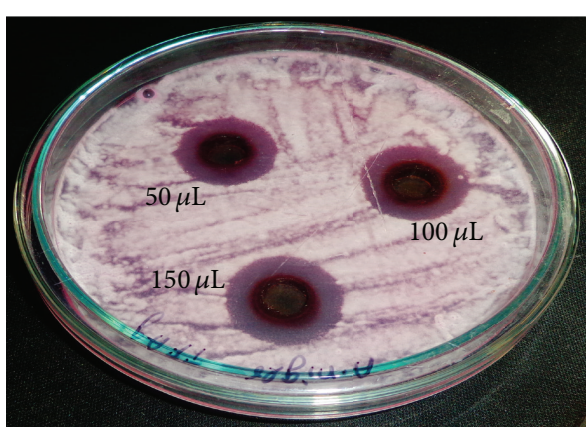

(b)

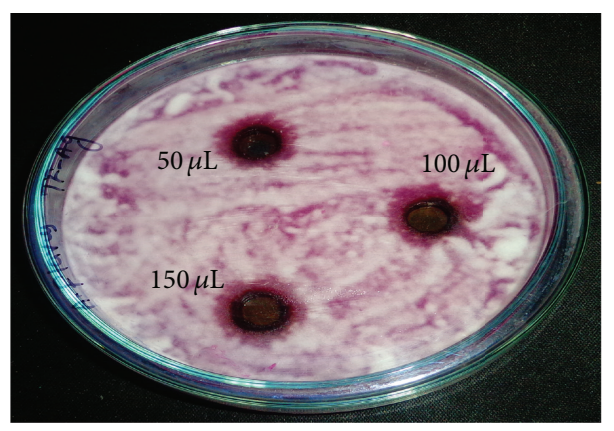

(c)

FIGURE 9: Antifungal activity of silver chloride nanoparticles synthesized by B. subtilis.

TABLE 1: Antifungal activity of silver chloride nanoparticles synthesized by B. subtilis. The maximum zone of inhibition was observed at $150 \mu \mathrm{L}$ concentration of silver chloride nanoparticles.

\begin{tabular}{lcccc}
\hline \multirow{2}{*}{ S. No } & Fungus & \multicolumn{3}{c}{$\begin{array}{c}\text { Concentration of silver chloride nanoparticles } \\
\text { Zone of inhibition in mm }\end{array}$} \\
& & $50 \mu \mathrm{L}$ & $100 \mu \mathrm{L}$ & $150 \mu \mathrm{L}$ \\
\hline 1 & Candida albicans & $16.30 \pm 0.208$ & $17.03 \pm 0.034$ & $17.97 \pm 0.261$ \\
2 & Aspergillus niger & $14.16 \pm 0.334$ & $15.47 \pm 0.291$ & $16.33 \pm 0.883$ \\
3 & Aspergillus flavus & $06.50 \pm 0.500$ & $07.00 \pm 0.578$ & $09.17 \pm 0.167$ \\
\hline
\end{tabular}

in the extracellular membrane of $B$. subtilis that might be involved in the synthesis of silver chloride nanoparticles. Similarly, Kalimuthu et al. have reported that the silver nanoparticles could be produced by Bacillus licheniformis with the assistance of NADH-dependent nitrate reductase enzyme [4]. Our observation is correlated with the reports of Ahamed et al. [6] and Durán et al. [18]. In addition, the stationary phase is the elongation phase of bacterial cells and it could be considered as an active phase for the production of silver chloride nanoparticles.

3.8. Antifungal Activity of Silver Chloride Nanoparticles. The antifungal activity of synthesized silver chloride nanoparticles is determined using disc diffusion assay against Candida albicans, Aspergillus flavus, and Aspergillus niger after 5 days of exposure (Figure 9). There are enormous reports available to exemplify the antifungal property of the silver nanoparticles. Very few reports are available to explain the antifungal and antibacterial property of silver chloride nanoparticles. Thus, the present investigation demonstrates the biobased synthesis and antifungal property of silver chloride nanoparticles. The zone is formed around the disc with the pellets at different concentrations $50 \mu \mathrm{L}, 100 \mu \mathrm{L}$, and $150 \mu \mathrm{L}$ of the diluted silver chloride nanoparticles (1:5 dilution). The Candida albicans, Aspergillus flavus, and Aspergillus niger show that the admirable zone of inhibition was $17.97 \pm 0.261$, $09.17 \pm 0.167$, and $16.33 \pm 0.883$, respectively, observed at $150 \mu \mathrm{L}$ concentration (Table 1 ). Table 1 shows that the zone of inhibition increases with increasing the concentration of silver chloride nanoparticles. In that, the Candida albicans and Aspergillus niger are more sensitive to silver chloride nanoparticles. Obviously, the results demonstrate that newly biosynthesized silver chloride nanoparticles are found to be highly toxic against fungal species. Therefore, synthesized silver chloride nanoparticle is a good source which is easily produced and extensively useful in biomedical application. Previously, the antibacterial activity of silver chloride was 
examined against E. coli [39]. Recently, Gopinath et al. reported the antibacterial activity of silver chloride nanoparticles against Gram-positive bacteria Staphylococcus aureus and Streptococcus pyogenes and Gram-negative bacteria E. coli and Proteus vulgaris [23]. There are no previous reports available to explain the possible mechanisms of antifungal activity of silver chloride nanoparticles. But, according to our knowledge, this is the first report to examine the antifungal activity of silver chloride nanoparticles. We are expanding our research to examine the effect of silver chloride nanoparticles on bacterial cells.

\section{Conclusion}

The present investigation demonstrated the ecofriendly biofabrication of silver chloride nanoparticles using the biomass of Bacillus subtilis MTCC 3053. The presence of strong peak in the $400 \mathrm{~nm}$ revealed the formation of silver chloride nanoparticles and the TEM used for particle size determination that ranges from 20 to $60 \mathrm{~nm}$. The SDS-PAGE and FTIR analysis confirmed that the presence of reducing agent in the biomass might be responsible for the synthesis of silver chloride nanoparticles. In addition, the presence of intense band with $37 \mathrm{kDa}$ in SDS-PAGE exhibits the interaction of a protein with silver chloride ions that leads to the formation of silver chloride nanoparticles. The antifungal activity of silver chloride nanoparticles is examined against Candida albicans and Aspergillus niger that show more zone of inhibition when compared to the Aspergillus flavus. The Candida albicans and Aspergillus niger are susceptible to silver chloride nanoparticles, whereas Aspergillus flavus have little resistant property against silver chloride nanoparticles. We are currently involved to examine the interaction between the silver chloride ions and Aspergillus flavus. This enzyme-based method is beneficial for enormous production of silver chloride nanoparticles by downstream process. However, there is an investigation undergoing to identify the exact interaction between the protein and silver chloride nanoparticles.

\section{Conflict of Interests}

The authors have no competing interests in the future.

\section{Acknowledgments}

Kanniah Paulkumar thanks CSIR for providing the fellowship through CSIR-SRF and the authors acknowledge DST for FIST Grant (ref. no. S/FST/ESI-101/2010), Karunya University for SEM EDAX and XRD analyses, and IIT Bombay for TEM analysis. The authors thank R. Arunachalam for his fruitful comments.

\section{References}

[1] J. R. Lloyd, "Bioremediation of metals; the application of microorganisms that make and break minerals," Microbiology Today, vol. 29, pp. 67-69, 2002.
[2] D. H. Nies, "Microbial heavy-metal resistance," Applied Microbiology and Biotechnology, vol. 51, no. 6, pp. 730-750, 1999.

[3] S. Silver and L. T. Phung, "Bacterial heavy metal resistance: new surprises," Annual Review of Microbiology, vol. 50, pp. 753-789, 1996.

[4] K. Kalimuthu, R. S. Babu, D. Venkataraman, M. Bilal, and S. Gurunathan, "Biosynthesis of silver nanocrystals by Bacillus licheniformis," Colloids and Surfaces B, vol. 65, no. 1, pp. 150-153, 2008.

[5] K. Kalishwaralal, V. Deepak, S. Ramkumarpandian, H. Nellaiah, and G. Sangiliyandi, "Extracellular biosynthesis of silver nanoparticles by the culture supernatant of Bacillus licheniformis," Materials Letters, vol. 62, no. 29, pp. 4411-4413, 2008.

[6] A. Ahmad, P. Mukherjee, S. Senapati et al., "Extracellular biosynthesis of silver nanoparticles using the fungus Fusarium oxysporum," Colloids and Surfaces B, vol. 28, no. 4, pp. 313-318, 2003.

[7] P. Mukherjee, A. Ahmad, D. Mandal et al., "Fungus-mediated synthesis of silver nanoparticles and their immobilization in the mycelial matrix: a novel biological approach to nanoparticle synthesis," Nano Letters, vol. 1, no. 10, pp. 515-519, 2001.

[8] S. Kundu, K. Wang, and H. Liang, "Size-controlled synthesis and self-assembly of silver nanoparticles within a minute using microwave irradiation," Journal of Physical Chemistry C, vol. 113, no. 1, pp. 134-141, 2009.

[9] Y. C. Liu and L. H. Lin, "New pathway for the synthesis of ultrafine silver nanoparticles from bulk silver substrates in aqueous solutions by sonoelectrochemical methods," Electrochemistry Communications, vol. 6, no. 11, pp. 1163-1168, 2004.

[10] G. Sandmann, H. Dietz, and W. Plieth, "Preparation of silver nanoparticles on ITO surfaces by a double-pulse method," Journal of Electroanalytical Chemistry, vol. 491, no. 1-2, pp. 78$86,2000$.

[11] A. Pourahmad and S. Sohrabnezhad, "Preparation and characterization of Ag nanowires in mesoporous MCM-41 nanoparticles template by chemical reduction method," Journal of Alloys and Compounds, vol. 484, no. 1-2, pp. 314-316, 2009.

[12] S. A. Vorobyova, A. I. Lesnikovich, and N. S. Sobal, "Preparation of silver nanoparticles by interphase reduction," Colloids and Surfaces A, vol. 152, no. 3, pp. 375-379, 1999.

[13] D.-G. Yu, "Formation of colloidal silver nanoparticles stabilized by $\mathrm{Na}+-\operatorname{poly}(\gamma$-glutamic acid)-silver nitrate complex via chemical reduction process," Colloids and Surfaces B, vol. 59, no. 2, pp. 171-178, 2007.

[14] T. R. Ravindran, A. K. Arora, B. Balamurugan, and B. R. Mehta, "In homogeneous broadening in the photoluminescence spectrum of CdS nanoparticles," Nanostructured Materials, vol. 11, no. 5, pp. 603-609, 1999.

[15] M. Pattabi and J. Uchil, "Synthesis of cadmium sulphide nanoparticles," Solar Energy Materials and Solar Cells, vol. 63, no. 4, pp. 309-314, 2000.

[16] H. Bar, D. K. Bhui, G. P. Sahoo, P. Sarkar, S. Pyne, and A. Misra, "Green synthesis of silver nanoparticles using seed extract of Jatropha curcas," Colloids and Surfaces A, vol. 348, no. 1-3, pp. 212-216, 2009.

[17] A. Ahmad, P. Mukherjee, D. Mandal et al., "Enzyme mediated extracellular synthesis of CdS nanoparticles by the fungus, Fusarium oxysporum," Journal of the American Chemical Society, vol. 124, no. 41, pp. 12108-12109, 2002.

[18] N. Durán, P. D. Marcato, O. L. Alves, G. I. H. de Souza, and E. Esposito, "Mechanistic aspects of biosynthesis of silver 
nanoparticles by several Fusarium oxysporum strains," Journal of Nanobiotechnology, vol. 3, no. 8, 2005.

[19] S. He, Z. Guo, Y. Zhang, S. Zhang, J. Wang, and N. Gu, "Biosynthesis of gold nanoparticles using the bacteria Rhodopseudomonas capsulata," Materials Letters, vol. 61, no. 18, pp. 39843987, 2007.

[20] N. Jain, A. Bhargava, S. Majumdar, J. C. Tarafdar, and J. Panwar, "Extracellular biosynthesis and characterization of silver nanoparticles using Aspergillus flavus NJP08: a mechanism perspective," Nanoscale, vol. 3, no. 2, pp. 635-641, 2011.

[21] T. Klaus, R. Joerger, E. Olsson, and C. G. Granqvist, "Silverbased crystalline nanoparticles, microbially fabricated," Proceedings of the National Academy of Sciences of the United States of America, vol. 96, no. 24, pp. 13611-13614, 1999.

[22] R. M. Slawson, J. T. Trevors, and H. Lee, "Silver accumulation and resistance in Pseudomonas stutzeri," Archives of Microbiology, vol. 158, no. 6, pp. 398-404, 1992.

[23] V. Gopinath, S. Priyadarshini, N. M. Priyadharsshini, K. Pandian, and P. Velusamy, "Biogenic synthesis of antibacterial silver chloride nanoparticles using leaf extracts of Cissus quadrangularis Linn," Materials Letters, vol. 91, pp. 224-227, 2013.

[24] P. Huo, Y. Yan, S. Li, H. Li, and W. Huang, "Floating photocatalysts of fly-ash cenospheres supported $\mathrm{AgCl} / \mathrm{TiO}_{2}$ films with enhanced Rhodamine B photodecomposition activity," Desalination, vol. 256, no. 1-3, pp. 196-200, 2010.

[25] H. Saijo, T. Kitamura, and H. Ohtani, "Adsorption of cyanine dyes on AgCl crystals studied by XPS," Surface Science, vol. 177, no. 2, pp. 431-443, 1986.

[26] W. Yan, X. Feng, X. Chen, X. Li, and J. J. Zhu, "A selective dopamine biosensor based on AgCl@polyaniline core-shell nanocomposites," Bioelectrochemistry, vol. 72, no. 1, pp. 21-27, 2008.

[27] M. Husein, E. Rodil, and J. H. Vera, "A novel method for the preparation of silver chloride nanoparticles starting from their solid powder using microemulsions," Journal of Colloid and Interface Science, vol. 288, no. 2, pp. 457-467, 2005.

[28] J. Bai, Y. Li, M. Li, S. Wang, C. Zhang, and Q. Yang, "Electrospinning method for the preparation of silver chloride nanoparticles in PVP nanofiber," Applied Surface Science, vol. 254, no. 15, pp. 4520-4523, 2008.

[29] A. R. Abbasi and A. Morsali, "Synthesis and characterization of $\mathrm{AgCl}$ nanoparticles under various solvents by ultrasound method," Journal of Inorganic and Organometallic Polymers and Materials, vol. 23, pp. 286-292, 2012.

[30] A. K. Giri, R. K. Patel, and S. S. Mahapatra, "Artificial neural network (ANN) approach for modelling of arsenic (III) biosorption from aqueous solution by living cells of bacillus cereus biomass," Chemical Engineering Journal, vol. 178, pp. 1525, 2011.

[31] M. Tuzen, E. Melek, and M. Soylak, "Solid-phase extraction of copper, iron and zinc ions on Bacillus thuringiensis israelensis loaded on Dowex optipore V-493," Journal of Hazardous Materials, vol. 159, no. 2-3, pp. 335-341, 2008.

[32] C. G. Ruiz, V. Rodriguez-Tirado, and B. Gomez-Gil, "Cadmium and zinc removal from aqueous solutions by Bacillus jeotgali: $\mathrm{pH}$, salinity and temperature effects," Bioresource Technology, vol. 99, no. 9, pp. 3864-3870, 2008.

[33] F. Çolak, N. Atar, D. Yazicioĝlu, and A. Olgun, "Biosorption of lead from aqueous solutions by Bacillus strains possessing heavy-metal resistance," Chemical Engineering Journal, vol. 173, no. 2, pp. 422-428, 2011.
[34] N. Pugazhenthiran, S. Anandan, G. Kathiravan, N. K. U. Prakash, S. Crawford, and M. Ashokkumar, "Microbial synthesis of silver nanoparticles by Bacillus sp," Journal of Nanoparticle Research, vol. 11, no. 7, pp. 1811-1815, 2009.

[35] A. Henglein, "Physicochemical properties of small metal particles in solution: "microelectrode" reactions, chemisorption, composite metal particles, and the atom-to-metal transition," Journal of Physical Chemistry, vol. 97, no. 21, pp. 5457-5471, 1993.

[36] M. Sastry, V. Patil, and S. R. Sainkar, "Electrostatically controlled diffusion of carboxylic acid derivatized silver colloidal particles in thermally evaporated fatty amine films," Journal of Physical Chemistry B, vol. 102, no. 8, pp. 1404-1410, 1998.

[37] A. R. Shahverdi, S. Minaeian, H. R. Shahverdi, H. Jamalifar, and A. A. Nohi, "Rapid synthesis of silver nanoparticles using culture supernatants of Enterobacteria: a novel biological approach," Process Biochemistry, vol. 42, no. 5, pp. 919-923, 2007.

[38] D. M. Ali, M. Sasikala, M. Gunasekaran, and N. Thajuddin, "Biosynthesis and characterization of silver nanoparticles using marine cyanobacterium, Oscillatoria willei NTDM01," Digest Journal of Nanomaterials and Biostructures, vol. 6, no. 2, pp. 385-390, 2011.

[39] B. Naik, V. Desai, M. Kowshik, V. S. Prasad, G. F. Fernando, and N. N. Ghosh, "Synthesis of Ag/AgCl-mesoporous silica nanocomposites using a simple aqueous solution-based chemical method and a study of their antibacterial activity on E. coli," Particuology, vol. 9, no. 3, pp. 243-247, 2011. 

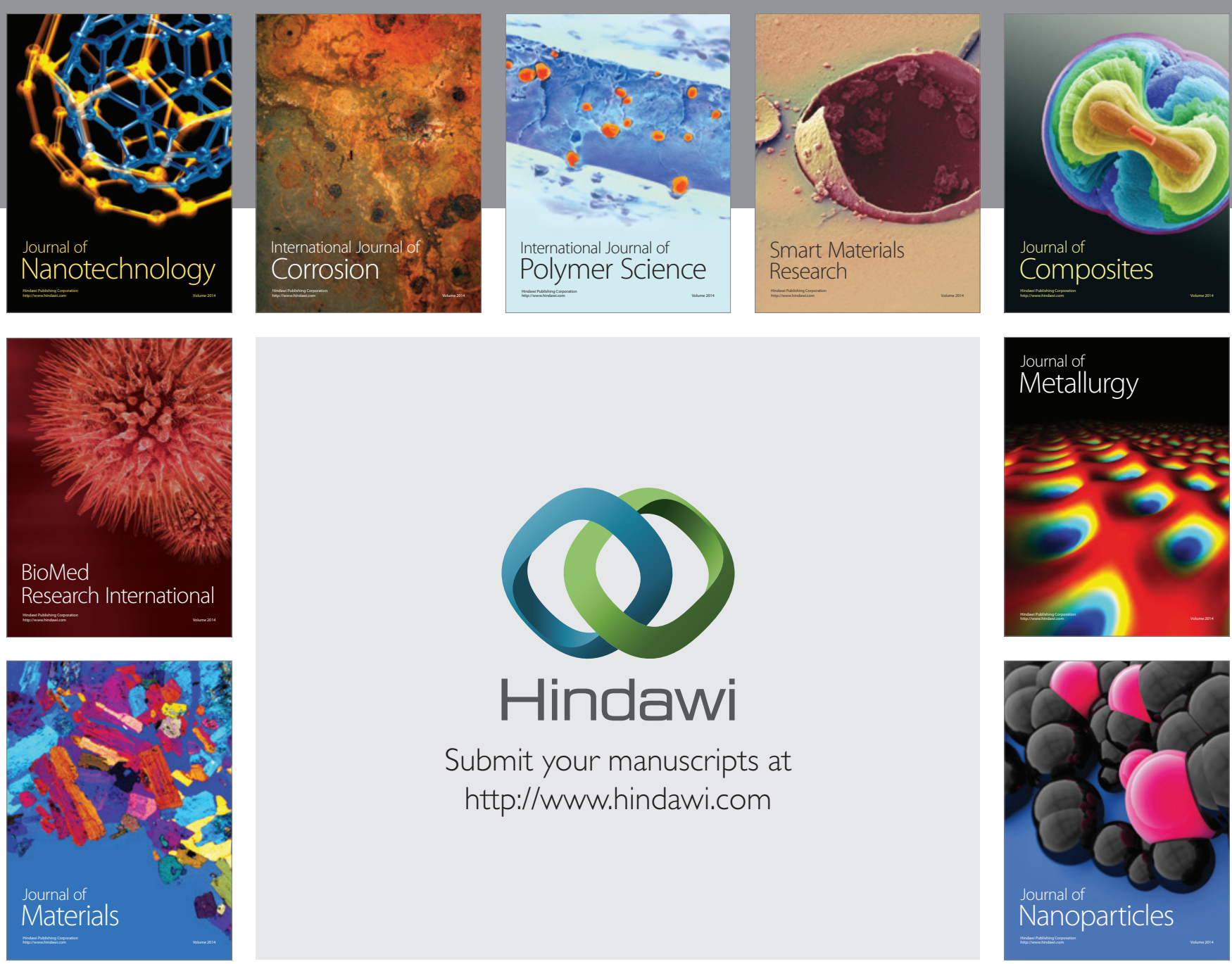

Submit your manuscripts at http://www.hindawi.com
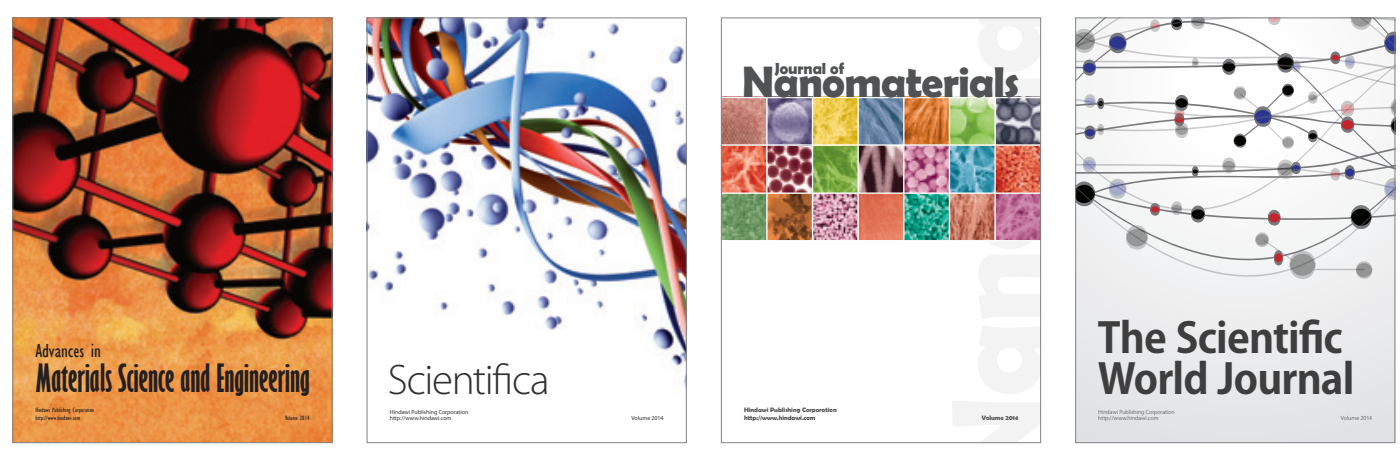

\section{The Scientific World Journal}
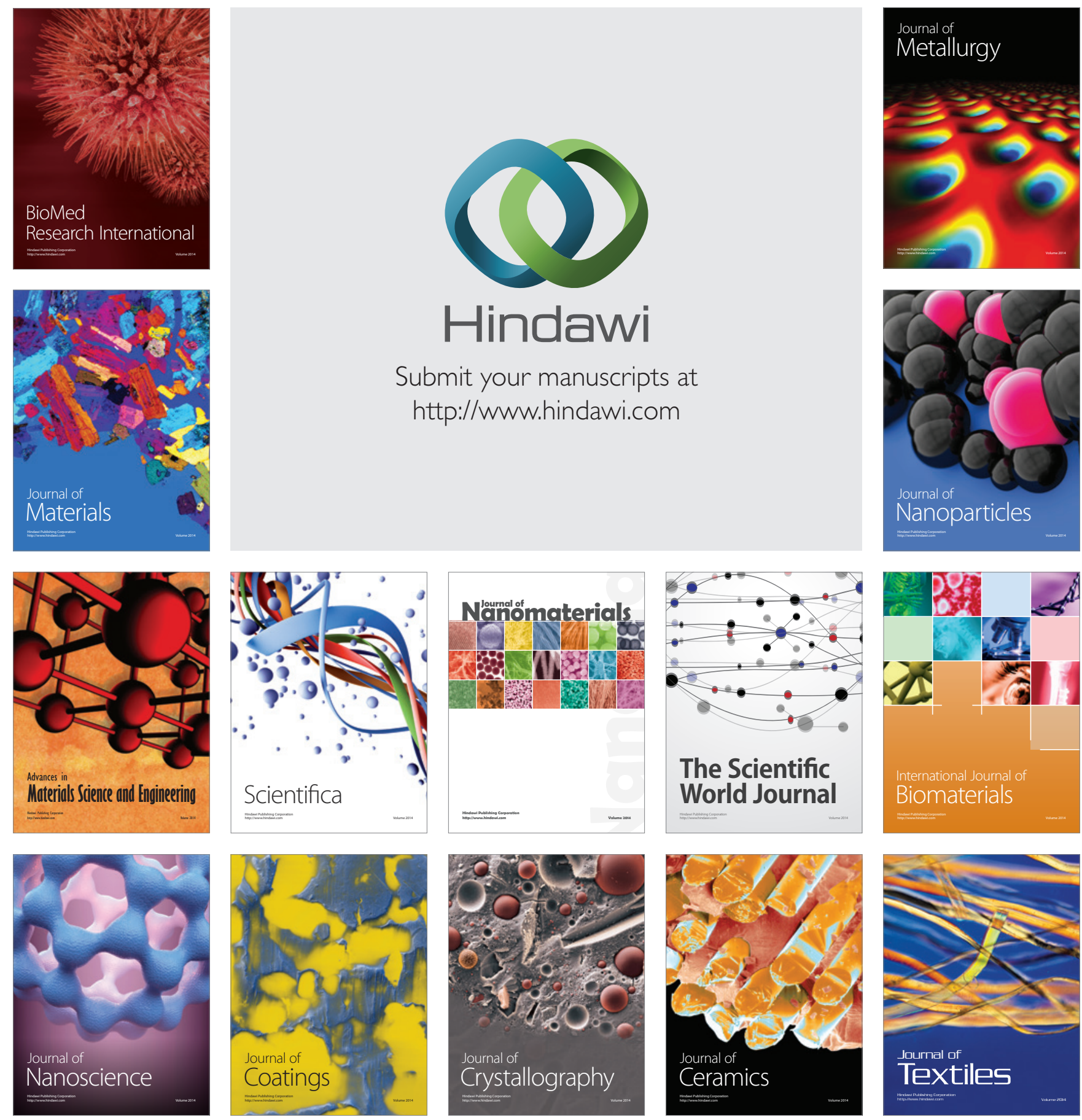